\section{Acid rain not only to blame}

\section{Donald Charles}

THE vision of pre-industrial society as ecologically neutral takes a knock on the head on page 824 of this issue ${ }^{1}$, with evidence from Renberg and colleagues that prehistoric agricultural practices noticeably altered the $\mathrm{pH}$ of lakes in Sweden. The changes were the opposite of those that are causing concern today - acidification - and were smaller. But they demonstrate the role that land use can have in controlling lake chemistry.

As concern has grown over lake acidification in diverse parts of Europe and North America during the past 20 years, the influence of changes in land use has become a prominent part of the debate. How important is land use compared with deposition of strong acids derived from the combustion of fossil fuels? Several hypotheses have it that land-use change, primarily growth of forest or development of heathlands following fires, logging and abandonment of agriculture, could have caused the recent acidification of low-alkalinity surface waters $^{2.3}$. To an extent, this is backed up by the work of Renberg et al., who provide evidence here and elsewhere ${ }^{4}$ of significant long-term regional effects on surface-water $\mathrm{pH}$, including an increase in $\mathrm{pH}$ (increased alkalinity) following conversion of forest to agricultural land and a decline in $\mathrm{pH}$ (acidification) following abandonment of agriculture. The full extent of the modern acidification, however, cannot be attributed to changed land use.

Renberg, Korsman and Birks use sediment composition to determine the effects of land-use change wrought by Iron Age peoples in 14 widely separated lakes in southern Sweden (where acid deposition is a severe problem today and a large proportion of lakes are acidified). Sediment cores were dated using ${ }^{210} \mathrm{~Pb}$ and ${ }^{14} \mathrm{C}$; vegetation and land use were determined from pollen; and lakewater $\mathrm{pH}$ was inferred from remains of diatoms ${ }^{5}$. The authors' ability to infer water chemistry quantitatively from sediment diatom assemblages is due to rapid developments over the past $5-10$ years. It is now possible to infer $\mathrm{pH}$ with a standard error of about $0.3 \mathrm{pH}$ units. This new tool has spurred many studies of acidification, and is being applied to other issues such as runaway algal growth and climate change.

Renberg et al. reconstructed the lakes' history over their entire lifetime (more than 10,000 years), and they compare the relative importance of the factors potentially responsible for acidification of surface waters. These factors include natural processes such as progressive leaching from the soil of base cations; removal of forests and replacement by agricultural activities during the Iron Age; regrowth of forests following abandonment of agricultural practices many centuries later; and acid deposition, beginning in the nineteenth century. They find that $\mathrm{pH}$ declined from about 7.0 to 5.5 over the first few thousand years following deglaciation, owing to natural processes. After deforestation and expansion of an agrarian economy during the Iron Age, pH increased by $0.5-1.4$ units in 12 of the 14 lakes. During the nineteenth and twentieth centuries, $\mathrm{pH}$ declined, in the past few decades to less than 5.0 in some lakes, a level toxic to many aquatic organisms. Though it is not possible to determine the relative roles of revegetation and acidic precipitation from this work alone, in conjunction with other studies ${ }^{6}$ Renberg et al. argue that the $\mathrm{pH}$ decrease to below 5.5 is due to acid precipitation.

In this study, Renberg et al. effectively perform natural experiments on lake acidification, with the advantage that the results are 'controlled' in that the same lakes are being examined as are recording the modern industrial assault. The results also cover much longer periods than are possible with modern experimental field studies and they are based on direct evidence of intercomparable past conditions.

The role of land use in modifying lake acidity is important not only in an overall scientific understanding of the process, but more urgently because of the need to control sulphur and nitrogen emissions, primarily from power plants. It is also relevant to management of individual lake-catchment systems. If land-use changes on a regional scale play a larger role in surface-water acidification than allowed for in government assessments, less need would be perceived to control emissions. On the other hand, if the role of land use is overestimated, then emission-reduction policies may be insufficient.

Donald Charles is in the Patrick Center for Environmental Research. Academy of Natural Sciences, 1900 Benjamin Franklin Parkway, Philadelphia, Pennsylvania 19103, USA.

1. Renberg, I. Korsman. T. \& Birks, H. J. B. Nature 362. 824827 (1993)

2. Rosenqvist, I. T. Sci. Total Environ. 10, 39-49 (1978).

3. Krug, E. C. \& Frink, C. R. Science 221, 520-525 (1983).

4. Renberg, I. Phil. Trans. R. Soc. B327, 357-361 (1990)

5. Birks, H. J. B. et al. Phil. Trans. R. Soc. B327, 263-278 (1990)

6. Battarbee, R. W. et al. Nature 314, 350-352 (1985)
King Coal, part II

COAL is an uncompetitive fuel. Its high ratio of carbon to hydrogen gives less heat and more carbon dioxide than oil and gas; it burns well only in large elaborate furnaces; it produces ash and sulphur dioxide. Worst of all, it has to be dug out of the ground by expensive skilled labour.

As a chemical feedstock, however, coal is still attractive. Its high proportion of carbon is an advantage here; so is its complex, benzenoid, easily disrupted molecular structure. It used to be the basis of the whole heavy organic chemical industry, and might be again. Daedalus now proposes, not the underground gasification of coal, but its underground polymerization.

Coal is approximately $\mathrm{C}_{10} \mathrm{H}_{7} \mathrm{O}$. It must have reached thermodynamic equilibrium over the years, and represents the most stable state for this composition. But a bit of added hydrogen or oxygen could tip the balance. The most stable state of $\mathrm{C}_{10} \mathrm{H}_{10}$ could well be polystyrene; that of $\mathrm{C}_{10} \mathrm{H}_{8} \mathrm{O}_{4}$ might be polyester. The copious benzene rings and potential carboxylic acid groups in coal suggest that these transformations might not be too difficult. The methane of the coal seam could also be oxidized to formaldehyde, the basis of the acetal polymers, or even to higher alcohols - the other half of the polyester molecule. All these thermoplastic polymers melt easily. Once formed in place, they could be extracted by the Frasch process - pumping superheated steam down a borehole to blow them to the surface in molten form.

So DREADCO chemists are using all the cunning of modern catalytic chemistry to polymerize coal in situ. They plan to pump a suspension of catalysts in steam and air or hydrogen, down into a coal seam. They will launch intense microwaves down the borehole to start the reaction, and will then pump down more reagents to keep it going. The seam will be converted into a vast bed of crude acetal/styrene/ester copolymer.

Thus coal will come into its own. Oil and gas will provide our energy: they are good at that. Coal will provide the raw material for the age of plastics. The crude geopolymer will of course have to be cleaned, purified and fractionated; in the process, its sulphur and nitrogen will be extracted and put to good chemical use. The miner, whose dangerous and unpleasant labour is so misguidedly romanticized, will be eliminated. But coal will still be king. David Jones 